\title{
EFEITOS DA INOCULAÇÃO COM BACTÉRIAS DIAZOTRÓFICAS E DA ADUBAÇÃO NITROGENADA NO CRESCIMENTO E NA QUALIDADE DE MUDAS DE Inga laurina (SW.) Willd. (Fabaceae) ${ }^{1}$
}

\author{
Gabriel Salles Góes ${ }^{2}$, Eduardo Gross ${ }^{3}$, Ediófila Brito-Rocha ${ }^{4}$ e Marcelo Schramm Mielke ${ }^{5}$
}

RESUMO - Inga laurina é uma espécie arbórea com ampla distribuição na América do Sul, útil para sistemas agroflorestais, restauração florestal e arborização urbana. Este estudo teve como objetivo avaliar os efeitos da inoculação com bactérias fixadoras de nitrogênio (N) e da adubação nitrogenada no crescimento e qualidade de mudas de I. laurina. O experimento teve duração de 170 dias, e as mudas foram cultivadas em tubetes plásticos com $115 \mathrm{~cm}^{3}$ de capacidade, contendo uma mistura 9:1 em volume de HS Florestal ${ }^{\circledR}$ e pó de fibra de coco como substrato. Foram analisados seis tratamentos, sendo quatro inoculações (Bradyrhizobium japonicum 1 - BJ1, Rhizobium miluonense-RM, Bradyrhizobium japonicum 2 - BJ2 e Burkholderia cepacia - BC), o controle positivo - $\mathrm{C}^{+}$(sem inoculação e com adubação nitrogenada semanal, $60 \mathrm{mg} \mathrm{dm}{ }^{3} \mathrm{de} \mathrm{N}$, na forma de ureia) e o controle negativo - $\mathrm{C}^{-}$(sem inoculação e sem adubação nitrogenada). Os tratamentos com inoculação foram pouco efetivos em relação ao crescimento das mudas, visto que as médias das variáveis de crescimento, da massa foliar específica (MFE) e do índice de qualidade de Dixon (IQD) foram significativamente superiores no $\mathrm{C}^{+}$, em comparação com os demais tratamentos. No entanto, os isolados RM e BJ2 foram efetivos na produção de nódulos, pois apresentaram os maiores valores médios da massa de matéria seca de nódulos (MSN). Além disso, os valores médios do índice de clorofila Falker (ICF) foram significativamente superiores nos tratamentos com inoculação em relação ao $\mathrm{C}^{-}$. Os melhores resultados entre os tratamentos com inoculação foram obtidos para RM, seguido de BJ2.

Palavras-chave: Bradyrhizobium; Burkholderia; Rhizobium.

\section{EFFECTS OF INOCULATION WITH DIAZOTROPHIC BACTERIA AND NITROGEN FERTILIZATION ON GROWTH AND QUALITY OF Inga laurina (SW.) Willd. (Fabaceae) SEEDLINGS}

\begin{abstract}
Inga laurina is a tree species widespread in South America, useful for agroforestry, forest restoration and urban forestry. This study aimed to evaluate the effects of inoculation with nitrogen (N) fixing bacteria and $N$ fertilization on growth and quality of I. laurina seedlings. The experiment lasted 170 days and the seedlings were grown in plastic tubes with $115 \mathrm{~cm}^{3}$ capacity, containing a mixture 9:1 by volume of HS Florestal $\mathbb{R}$ and coconut coir dust as substrate. Six treatments were tested, with four separate inoculations (Bradyrhizobium japonicum 1 - BJ1, Rhizobium miluonense-RM, Bradyrhizobium japonicum 2 - BJ2 and Burkholderia cepacia $-B C$ ), a positive control $-C^{+}$(without inoculation and with weekly $N$ fertilization, $60 \mathrm{mg} \mathrm{dm}^{3}$ of $N$ as urea) and a negative control $-C^{-}$(without inoculation and $N$ fertilization). The treatments with inoculation were ineffective in relation to the growth of seedlings, since the average values of growth variables, specific leaf mass (SLM) and Dixon quality index (DQI) were significantly higher in the $C^{+}$compared to the other treatments. Nevertheless, the isolates RM and BJ2 were effective in the production of nodules, since they showed
\end{abstract}

\footnotetext{
${ }^{1}$ Recebido em 17.12.2014 aceito para publicação em 21.10.2015.

${ }^{2}$ Universidade Estadual de Santa Cruz, Mestrado em Produção Vegetal, Ilhéus, BA - Brasil. E-mail: <gsgóes@gmail.br>.

${ }^{3}$ Universidade Estadual de Santa Cruz, Departamento de Ciências Agrárias e Ambientais, Ilhéus, BA- Brasil. E-mail:<egross@uesc.br>.

${ }^{4}$ Universidade Estadual de Santa Cruz, Mestrado em Botânica, Ilhéus, BA - Brasil. E-mail: <ilabritorocha@gmail.br>.

${ }^{5}$ Universidade Estadual de Santa Cruz, Departamento de Ciências Biológicas, Ilhéus, BA - Brasil. E-mail: <msmielke@uesc.br>.
} 
the highest average values of the dry mass of nodules (DMN). Moreover, the average values of Falker chlorophyll index (FCI) were significantly higher in inoculated treatments with respect to $C^{-}$. The best results among the inoculation treatments were obtained for RM, followed by BJ2.

\section{Keywords: Bradyrhizobium; Burkholderia; Rhizobium.}

\section{INTRODUÇÃO}

Inga laurina (Sw.) Willd. (Fabaceae) é uma espécie arbórea com ampla distribuição na América do Sul, útil para sistemas agroflorestais, restauração florestal e arborização urbana (LORENZI, 2008). É uma espécie comum no Sul do Estado da Bahia, Brasil, uma região com alta diversidade e elevado endemismo, mas cuja contínua redução e fragmentação dos remanescentes florestais desprotegidos têm comprometidas a manutenção da biodiversidade em longo prazo (SCHROTH et al., 2011). A importância de leguminosas (Fabaceae) arbóreas na recuperação de ambientes degradados é largamente reconhecida, devido à sua capacidade de nodulação para fixação biológica do nitrogênio (ADAMS et al., 2010; CHAER et al., 2011). Nos neotrópicos, os ingás (Inga spp.) têm-se destacado como espécies nativas para a restauração de florestas degradadas e uso agroflorestal (JOSLIN et al., 2011; LOJKA et al., 2012).

A produção de mudas em viveiros florestais é um processo produtivo que requer o uso de equipamentos e insumos e necessita de retorno econômico em curto e médio prazos. Assim, a avaliação do crescimento de mudas, como resposta aos tratos culturais, incluindo a adubação, é fundamental para que o viveirista possa planejar seus custos de produção e prazos para a entrega das mudas (CARNEIRO, 1995). No entanto, a qualidade das mudas é fator de grande importância, principalmente, nos primeiros meses após o plantio, quando elas são submetidas a condições ambientais mais adversas do que aquelas preponderantes nos viveiros florestais (GROSSNICKLE, 2012).

O uso de atributos morfológicos que incluam mais de uma varável, como o comprimento e diâmetro do caule ou a massa de matéria seca de raízes e parte aérea, permite a obtenção de informações precisas sobre a qualidade das mudas. O índice de qualidade de Dickson (IQD) foi originalmente proposto para a produção de mudas de Picea glauca e Pinus strobus (DICKSON et al., 1960) e leva em conta as proporções entre massa de matéria seca total, de raízes e da parte aérea, além do comprimento e diâmetro do caule. Esse índice foi criado a partir de fórmulas, com diferentes combinações dos parâmetros morfológicos, comparadas com a avaliação da qualidade por viveiristas experientes. Além do IQD, outros atributos morfológicos podem ser indicadores da qualidade das mudas, como o quociente de robustez (ou razão entre o comprimento e o diâmetro do caule) (MAÑAS et al., 2009). A análise nutricional também é indicadora da qualidade de mudas, principalmente quanto ao teor de nitrogênio $(\mathrm{N})$ foliar. Nesse aspecto, merecem destaque os clorofilômetros, os quais podem ser utilizados como ferramentas não destrutivas para a avaliação do conteúdo de $\mathrm{N}$ em plantas e a integridade do aparelho fotossintético (TORRESNETTO et al., 2005; MIELKE et al., 2010; DANTAS et al., 2012). Esses equipamentos podem ser usados como indicadores do conteúdo do $\mathrm{N}$ em mudas, pelo fato de que grande parte do $\mathrm{N}$ foliar se encontra nas clorofilas (EVANS, 1989).

Na produção de mudas de leguminosas, alguns estudos demonstraram o efeito positivo da inoculação com bactérias fixadoras de $\mathrm{N}$ no crescimento das plantas (JAYAKUMAR; TAN, 2006; MAIA; SCOTTI, 2010). A associação com organismos diazotróficos eficientes pode permitir a supressão da adubação nitrogenada mineral, o que, além de reduzir custos, evita a lixiviação desse nutriente para o ambiente e os impactos oriundos de sua produção (MAIA; SCOTTI, 2010). Embora a produção de mudas de ingás não apresente maiores dificuldades, à exceção do fato de as sementes serem recalcitrantes (CARVALHO et al., 2003), estudos sobre a inoculação com bactérias diazotróficas na produção de mudas de espécies do gênero Inga spp. em ambiente de viveiro ainda são incipientes, sobretudo no sistema de produção em tubetes. Assim, este estudo teve como objetivo avaliar os efeitos da inoculação com bactérias fixadoras de $\mathrm{N}$ e da adubação nitrogenada no crescimento e qualidade de mudas de I. laurina, visando ao seu uso em projetos de restauração florestal.

\section{MATERIAL E MÉTODOS}

O experimento foi realizado no Viveiro Comunitário Floresta Viva (www.florestaviva.org.br) em Serra Grande, Uruçuca, no Estado da Bahia. O viveiro apresenta as laterais e o teto cobertos com tela plástica preta com 
aproximadamente $50 \%$ de sombreamento. As sementes foram coletadas em matrizes adjacentes à estrada IlhéusItacaré (BA-001), em ambiente de restinga. Realizou-se a semeadura indireta em areia, e após duas semanas efetuou-se a repicagem para tubetes de $115 \mathrm{~cm}^{3}$. No momento da repicagem foram amostradas 10 mudas para avaliações de altura, diâmetro, área foliar e massa de matéria seca no tempo inicial.

Devido à heterogeneidade da incidência de ventos, trânsito de pessoal e funcionamento dos aspersores do sistema de irrigação dentro do viveiro, foi adotado o delineamento experimental em blocos completos casualizados generalizados, ou seja, com repetições dentro dos blocos (ADDELMAN, 1969). Os blocos foram distribuídos aleatoriamente nas bancadas e formados por bandejas dispostas agrupadas. $O$ experimento foi composto por seis tratamentos, quatro blocos e quatro repetições por blocos, sendo cada unidade experimental constituída de quatro mudas. Os seis tratamentos foram distribuídos aleatoriamente em colunas, dentro de cada bloco, e o experimento contou com 384 mudas úteis (excluindo-se as bordaduras).

Os tratamentos foram constituídos de quatro isolados bacterianos, o controle positivo (com adubação nitrogenada) e o controle negativo (sem inoculação e adubação nitrogenada). Os isolados bacterianos foram fornecidos pelo Centro de Biotecnologia e Genética da Universidade Estadual de Santa Cruz (CBG/UESC). Esses isolados foram inoculados com o auxílio de uma micropipeta, uma semana após a repicagem das mudas, e constavam das seguintes bactérias: Bradyrhizobium japonicum (BJ1), Rhizobium miluonense (RM), Bradyrhizobium japonicum (BJ2) e Burkholderia cepacia $(\mathrm{BC})$.

O substrato utilizado foi o HS Florestal ${ }^{\circledR}$ (HS) (www.holambrasubstratos.com.br) em mistura com pó de coco (PC) (www.amafibra.com.br), na proporção de 9:1 em volume. As adubações foram realizadas com o auxílio de uma seringa pistola, para deposição de $1 \mathrm{~mL}$ de solução por tubete. Efetuou-se adubação de base com fosfato monoamônico (MAP), na dose de $150 \mathrm{mg} \mathrm{dm}^{-3}$ de fósforo, logo após o enchimento dos recipientes com substrato. As adubações de cobertura foram realizadas semanalmente, com $30 \mathrm{mg} \mathrm{dm}^{-3} \mathrm{de}$ potássio $(\mathrm{K})$, na forma de cloreto de $\mathrm{K}$, para todos os tratamentos, enquanto o controle positivo recebeu, também, adubação nitrogenada na dose de $60 \mathrm{mg} \mathrm{dm}^{-3}$ de N, na forma de ureia. As adubações de cobertura iniciaram a partir da quarta semana após a repicagem e ocorriam sempre no final da tarde. Com a intenção de testar a inoculação dentro das condições comuns de um viveiro comercial para produção de mudas, nenhum componente do sistema de produção passou por esterilização (sementes, tubetes, areia de semeadura, substratos, água e ferramentas).

O experimento teve duração total de 170 dias, entre 14/04 e 01/10/2012. Durante todo o período de execução do experimento, a radiação fotossinteticamente ativa (RFA) no interior do viveiro e a pleno sol foi monitorada por meio de sensores de radiação luminosa S-LIA-M003, acoplados a uma estação meteorológica Hobo Station Data Logger (Onset Computer, Massachusetts, USA). A temperatura (Ta) e a umidade relativa do ar (UR) foram monitoradas utilizando sensores acoplados à mesma estação meteorológica utilizada para a coleta de dados de RFA. Para cada dia foram calculadas as temperaturas média, máxima e mínima. A partir dos valores de Ta e UR, foi calculado o déficit de pressão de vapor do ar (DPV). Os valores médios da RFA total diária ao longo do experimento, no viveiro e a pleno sol, foram, respectivamente, $14,0 \pm 3,8 \mathrm{~mol} \mathrm{~m}^{-2} \mathrm{dia}^{-1}$ e $34,4 \pm 8,8$ mol m $\mathrm{m}^{-2} \mathrm{dia}^{-1}$. Os valores médios de Ta média, Ta máxima, Ta mínima e DPV máximo ao longo do experimento foram, respectivamente, de $22,1 \pm 1,1^{\circ} \mathrm{C} ; 26,7 \pm 1,3{ }^{\circ} \mathrm{C} ; 18,6$ $\pm 1,5^{\circ} \mathrm{C}$; e $1,0 \pm 0,3 \mathrm{kPa}$.

Ao final do experimento foram avaliados o diâmetro do coleto (D) e o comprimento do caule (C), com o auxílio de um paquímetro digital; a área foliar (AF), por meio de um medidor de área LI-3100 (Li-Cor, inc. Lincoln, Nebraska, USA); a massa de matéria seca de raízes (MSR), caules (MSC) e folhas (MSF), após a secagem em estufa de circulação forçada de ar a $70^{\circ} \mathrm{C}$ até massa constante; e a massa de matéria seca de nódulos (MSN), após a secagem por três dias em sílicagel. A partir desses valores, foram calculadas a taxa de crescimento relativo (TCR) e a taxa assimilatória líquida (TAL), com indicadores do crescimento, quociente de robustez (C/D), índice de qualidade de Dickson (IQD) e massa foliar específica (MFE), como indicadores da qualidade das mudas. A TCR, a TAL e a MFE foram calculadas segundo Hunt (1990) e o IQD, segundo Dickson et al. (1960). Além dessas variáveis, foram também utilizados como indicadoras da qualidade das mudas a MSN e o Índice de Clorofila Falker, o qual foi obtido por meio de um ClorofiLog (Falker, Porto 
Alegre, Brasil). O ICF foi obtido a partir da média de três medições, nos folíolos da segunda folha a partir de um dos ápices ( $1^{\mathrm{a}}$ folha madura). Esse aparelho retorna valores adimensionais relativos ao teor de clorofila $a(\mathrm{ICF} a)$, clorofila $b(\mathrm{ICF} b)$ e clorofila total (ICF $t)$.

Os efeitos dos tratamentos nas variáveis TCR, TAL, C/D, IQD, MFE, MSN, ICF $a$, ICF $b$ e ICF $t$ foram analisados mediante a análise de variância (ANOVA), seguida pelo teste de comparação de médias de ScottKnott a 5\% de probabilidade.

\section{RESULTADOS}

As médias da TCR e da TAL no tratamento $\mathrm{C}^{+}$ foram significativamente superiores em relação a todos os demais tratamentos (Tabela 1). O valor médio da TCR no tratamento $\mathrm{C}^{+}$foi $21 \%$ e $29 \%$ superior em relação aos tratamentos $\mathrm{C}^{-}$e BC, respectivamente. Da mesma forma, o valor médio da TAL foi de $21 \%$ e $39 \%$ superior no tratamento $\mathrm{C}^{+}$em relação aos tratamentos $\mathrm{C}^{-}$e $\mathrm{BJ} 2$, respectivamente. O valor médio da TCR foi significativamente superior no tratamento $\mathrm{RM}$ em relação aos demais tratamentos, com inoculação (BJ1, BJ2 e $\mathrm{BC})$.

Os valores médios de C/D não diferiram significativamente entre os tratamentos $\mathrm{BJ} 1, \mathrm{RM}, \mathrm{BJ} 2$, $\mathrm{BC} \mathrm{e} \mathrm{C}^{+}$, os quais foram significativamente superiores ao $\mathrm{C}^{-}$(Tabela 2). O valor médio do IQD foi significativamente superior no $\mathrm{C}^{+}$em relação aos demais tratamentos, sendo $102 \%$ e $169 \%$ maiores no $\mathrm{C}^{+}$com relação aos tratamentos $\mathrm{C}^{-}$e $\mathrm{BC}$, respectivamente. $\mathrm{O}$ valor médio da MFE no $\mathrm{C}^{+}$foi significativamente superior em relação aos demais tratamentos, os quais não diferiram significativamente entre si. Os valores médios da MSN nos tratamentos RM e BJ2 foram significativamente superiores em relação aos demais, sendo o menor valor médio de MSN obtido no $\mathrm{C}^{+}$. O valor médio de $\mathrm{MSN}$ foi $125 \%$ superior no tratamento RM em relação ao $\mathrm{C}^{+}$. Entre os tratamentos com inoculação, os valores médios de IQD para o tratamento RM foram significativamente superiores em relação aos tratamentos $\mathrm{BJ} 1, \mathrm{BJ} 2 \mathrm{e} \mathrm{BC}$.

Os valores médios de ICF (tanto ICF $a$, ICF $b$ e ICF $t$ ) no tratamento $\mathrm{C}^{+}$foram significativamente superiores em relação aos demais (Tabela 3). Nesses casos, os menores valores médios de ICF $a$, ICF $b$ e ICF $t$ foram obtidos no tratamento $\mathrm{C}^{-}$. Os valores médios de $\mathrm{ICF} a, \mathrm{ICF} b$ e ICF $t$ foram, respectivamente, $41 \%, 87 \%$ e $52 \%$ inferiores no tratamento $\mathrm{C}^{-}$em relação ao $\mathrm{C}^{+}$. Nos tratamentos em que foram realizadas as inoculações, os maiores valores médios foram obtidos para RM e BJ2, sendo os valores médios de ICF $t$, nesses tratamentos, aproximadamente $19 \%$ menores em relação ao tratamento $\mathrm{C}^{+}$.

\section{DISCUSSÃO}

Assim como neste estudo, são frequentes os casos em que os controles positivos apresentam resultados superiores aos tratamentos com inoculação. Em experimento com quatro leguminosas, entre elas I. laurina, os tratamentos que receberam adubação nitrogenada e fosfatada apresentaram médias de crescimento muito superiores em relação aos tratamentos com inoculação (PATREZE; CORDEIRO, 2005). Plantas inoculadas de Anadenanthera peregrina também tiveram associação com baixa eficiência (GROSS et al., 2002). Entretanto, também existem casos em que a inoculação foi eficiente. Em estudo com Acacia mangium, a inoculação com estirpes de Bradyrhizobium proporcionou biomassa semelhante à adubação nitrogenada (JAYAKUMAR; TAN, 2006). Em Inga vera, as plantas inoculadas não diferiram daquelas tratadas com adubação nitrogenada mineral para a massa de matéria seca aérea, e os melhores resultados foram obtidos com as mudas cultivadas

Tabela 1 - Taxa de crescimento relativo (TCR, $\left.\mathrm{mg} \mathrm{g}^{-1} \mathrm{dia}^{-1}\right)$ e taxa assimilatória líquida (TAL, $\left.\mathrm{g} \mathrm{cm}^{-2} \mathrm{dia}^{-1}\right)$ de mudas de I. laurina aos 170 dias após a repicagem. B. japonicum (BJ1), R. miluonense (RM), B. japonicum (BJ2), B. cepacia $(\mathrm{BC})$, controle positivo $\left(\mathrm{C}^{+}\right)$e controle negativo $\left(\mathrm{C}^{-}\right)$.

Table 1 - Relative growth rate ( $R G R, m g g^{-1}$ day $\left.y^{-1}\right)$ and net assimilation rate ( $N A R, \mathrm{~g} \mathrm{~cm}^{-2}$ day $\left.y^{-1}\right)$ of I. laurina seedlings at 170 days after transplanting. B. japonicum (BJ1), R. miluonense (RM), B. japonicum (BJ2), B. cepacia (BC), positive control $\left(C^{+}\right)$and negative control $\left(C^{-}\right)$.

\begin{tabular}{ccccccc}
\hline & BJ1 & RM & BJ2 & BC & $\mathrm{C}^{+}$ \\
\hline TCR & $22,17 \pm 0,88 \mathrm{c}$ & $22,78 \pm 1,25 \mathrm{~b}$ & $22,45 \pm 1,42 \mathrm{c}$ & $21,78 \pm 1,07 \mathrm{c}$ & $28,16 \pm 0,67 \mathrm{a}$ & $23,21 \pm 0,92 \mathrm{~b}$ \\
TAL & $0,51 \pm 0,03 \mathrm{c}$ & $0,52 \pm 0,05 \mathrm{c}$ & $0,49 \pm 0,08 \mathrm{c}$ & $0,51 \pm 0,03 \mathrm{c}$ & $0,68 \pm 0,04 \mathrm{a}$ & $0,56 \pm 0,05 \mathrm{~b}$ \\
\hline
\end{tabular}

Médias seguidas por letras iguais na linha não diferem estatisticamente entre si, pelo teste de Scott-Knott a 5\% de significância.

Revista Árvore, Viçosa-MG, v.39, n.6, p.1031-1038, 2015 
Tabela 2 - Quociente de robustez $\left(\mathrm{C} / \mathrm{D}, \mathrm{cm} \mathrm{mm}^{-1}\right)$, índice de qualidade de Dickson (IQD), massa foliar específica (MFE, $\mathrm{g} \mathrm{m}^{-2}$ ) e massa de matéria seca de nódulos (MSN, g) de mudas de I. laurina aos 170 dias após a repicagem. $B$. japonicum $(\mathrm{BJ} 1)$, R. miluonense $(\mathrm{RM})$, B. japonicum $(\mathrm{BJ} 2)$, B. cepacia $(\mathrm{BC})$, controle positivo $\left(\mathrm{C}^{+}\right)$e controle negativo $\left(\mathrm{C}^{-}\right)$.

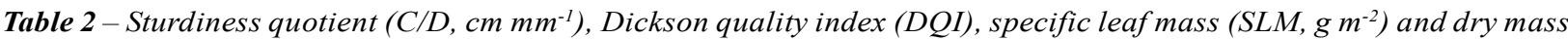
of nodules (DMN, $g$ ) of I. laurina seedlings at 170 days after transplanting. B. japonicum (BJ1), R. miluonense $(R M)$, B. japonicum (BJ2), B. cepacia $(B C)$, positive control $\left(C^{+}\right)$and negative control $\left(C^{-}\right)$.

\begin{tabular}{lcccccc}
\hline & BJ1 & RM & BJ2 & BC & $\mathrm{C}^{+}$ & $\mathrm{C}^{-}$ \\
\hline C/D & $4,02 \pm 0,36 \mathrm{a}$ & $3,96 \pm 0,73 \mathrm{a}$ & $4,16 \pm 0,65 \mathrm{a}$ & $3,78 \pm 0,47 \mathrm{~b}$ & $3,88 \pm 0,34 \mathrm{a}$ & $3,64 \pm 0,28 \mathrm{~b}$ \\
IQD & $0,37 \pm 0,07 \mathrm{c}$ & $0,43 \pm 0,11 \mathrm{~b}$ & $0,39 \pm 0,09 \mathrm{c}$ & $0,36 \pm 0,04 \mathrm{c}$ & $0,97 \pm 0,11 \mathrm{a}$ & $0,48 \pm 0,11 \mathrm{~b}$ \\
MFE & $86,84 \pm 4,99 \mathrm{~b}$ & $85,98 \pm 5,34 \mathrm{~b}$ & $83,67 \pm 10,65 \mathrm{~b}$ & $87,46 \pm 3,48 \mathrm{~b}$ & $91,32 \pm 3,85 \mathrm{a}$ & $87,16 \pm 6,31 \mathrm{~b}$ \\
MSN & $0,055 \pm 0,02 \mathrm{~b}$ & $0,093 \pm 0,06 \mathrm{a}$ & $0,080 \pm 0,05 \mathrm{a}$ & $0,057 \pm 0,04 \mathrm{~b}$ & $0,036 \pm 0,03 \mathrm{~b}$ & $0,064 \pm 0,05 \mathrm{~b}$ \\
\hline
\end{tabular}

Médias seguidas por letras iguais na linha não diferem estatisticamente entre si, pelo teste de Scott-Knott a 5\% de significância.

Tabela 3 - Índices de clorofila Falker (ICFs) para mudas de I. laurina aos 170 dias após a repicagem. B. japonicum (BJ1), R. miluonense (RM), B. japonicum (BJ2), B. cepacia $(\mathrm{BC})$, controle positivo $\left(\mathrm{C}^{+}\right)$e controle negativo $\left(\mathrm{C}^{-}\right)$. ICF $a$ (clorofila $a$ ), ICF $b$ (clorofila $b$ ) e ICF $t$ (clorofila total).

Table 3 - Falker chlorophyll indexes (FCIs) of I. laurina seedlings at 170 days after transplanting. B. japonicum (BJ1), R. miluonense (RM), B. japonicum (BJ2), B. cepacia $(B C)$, positive control $\left(C^{+}\right)$and negative control $\left(C^{-}\right) . F C I a$ (chlorophyll a), FCIb (chlorophyll b) and FCIt (total chlorophyll).

\begin{tabular}{ccccccc}
\hline & BJ1 & RM & BJ2 & BC & $C^{+}$ \\
\hline ICFa & $26,88 \pm 2,34 \mathrm{~b}$ & $28,39 \pm 1,88 \mathrm{~b}$ & $28,27 \pm 3,27 \mathrm{~b}$ & $26,28 \pm 3,00 \mathrm{~b}$ & $33,00 \pm 1,73 \mathrm{a}$ & $23,38 \pm 2,46 \mathrm{c}$ \\
$\mathrm{ICFb}$ & $8,86 \pm 2,27 \mathrm{c}$ & $9,88 \pm 2,12 \mathrm{~b}$ & $10,28 \pm 2,91 \mathrm{~b}$ & $8,47 \pm 2,65 \mathrm{c}$ & $12,94 \pm 1,52 \mathrm{a}$ & $6,92 \pm 1,42 \mathrm{~d}$ \\
$\mathrm{ICFt}$ & $35,74 \pm 4,52 \mathrm{~b}$ & $38,27 \pm 3,88 \mathrm{~b}$ & $38,56 \pm 6,10 \mathrm{~b}$ & $34,76 \pm 5,55 \mathrm{~b}$ & $45,94 \pm 3,14 \mathrm{a}$ & $30,30 \pm 3,81 \mathrm{c}$ \\
\hline
\end{tabular}

Médias seguidas por letras iguais na linha não diferem estatisticamente entre si, pelo teste de Scott-Knott a 5\% de significância.

com adubação orgânica, que apresentaram massa de matéria seca e conteúdo de nitrogênio e fósforo superiores (MAIA; SCOTTI, 2010).

A TCR e a TAL são duas variáveis amplamente utilizadas para a avaliação do crescimento de plantas. Enquanto a TCR indica o incremento em biomassa em dado período de tempo a partir da biomassa inicial, a TAL indica o incremento em biomassa em relação à área foliar disponível (HUNT, 1990) e apresenta relação direta com a taxa fotossintética líquida (MONTGOMERY, 2004; FEIJÓ et al., 2009). Uma vez que grande parte do $\mathrm{N}$ em plantas é alocada para o aparelho fotossintético, os maiores valores de TCR e TAL no $\mathrm{C}^{+}$são reflexos diretos do melhor estado nutricional dessas mudas em relação aos demais tratamentos (COSTE et al., 2005). No entanto, vários estudos têm demonstrado a eficiência dos clorofilômetros na estimativa do conteúdo de $\mathrm{N}$ foliar em espécies arbóreas de clima tropical (TORRESNETO et al., 2005; DANTAS et al., 2012) ou temperado (van den BERG; PERKINS, 2004). Assim, embora nesse experimento as mudas não tenham sido submetidas à análise nutricional, os maiores valores de ICF no
$\mathrm{C}^{+}$e nos tratamentos com maior MSN (RM e BJ2) indicam também maior capacidade de fixação biológica do $\mathrm{N}$ quando foram utilizados esses isolados.

Segundo Dumroese et al. (2009), em experimentos com substratos, plantas não inoculadas e não fertilizadas também podem apresentar nódulos. Esses autores propuseram que, nesses casos, a contaminação pode ter ocorrido pela deposição de partículas levadas pelo vento, pela ação humana, de outros animais ou por eventos de precipitação pluvial e irrigação. Neste estudo, nenhum componente do sistema de produção passou por esterilização. Optou-se, por isso, com o intuito de testar a inoculação dentro das condições comuns de um viveiro comercial para produção de mudas, pois o uso de autoclaves e, ou, produtos químicos para esterilização aumentam os custos e o impacto ambiental do processo. Assim, o fato de terem sido verificados nódulos no tratamento $\mathrm{C}^{-}$é indicativo da existência de contaminação por bactérias diazotróficas não isoladas.

É importante salientar que os valores médios de TCR e de IQD não diferiram significativamente entre 
os tratamentos $\mathrm{RM}$ e $\mathrm{C}^{-}$. Além disso, embora tenha sido verificada diferença significativa entre as médias de TAL para RM e C-, a diferença entre essas médias foi relativamente pequena (aproximadamente $8 \%$ ). Todavia, os valores médios da MSN e do ICF foram significativamente superiores no isolado RM em relação ao $\mathrm{C}^{-}$. Assim, considerando que mudas com maior quantidade de nódulos e com maiores teores de $\mathrm{N}$ e de clorofilas podem apresentar maior sobrevivência e crescimento no campo, o uso da inoculação pode ser considerada como técnica promissora para a produção de mudas de I. laurina em viveiros voltados para a restauração florestal.

Sabe-se que a alta fertilização nitrogenada inibe a formação de nódulos e a atividade da nitrogenase (PATREZE; CORDEIRO, 2005). Em estudo com leguminosas da Amazônia, as espécies analisadas apresentaram nodulação abundante quando cultivadas em solo sem adubação nitrogenada e sem inoculação, o que demonstrou a existência de bactérias nativas eficientes (MOREIRA, 1997). Como esperado, o $\mathrm{C}^{+}$ apresentou a menor MSN, apesar de não diferir estatisticamente do $\mathrm{C}^{-}$e dos tratamentos $\mathrm{BC}$ e BJ1. No entanto, os tratamentos RM e BJ2 tiveram nodulação significativamente superior ao $\mathrm{C}^{+}$e aos demais tratamentos. Embora as mudas inoculadas com esses isolados tenham apresentado menor crescimento, IQD e MFE em comparação ao $\mathrm{C}^{+}$, os maiores valores médios de MSN podem ser indicativos de uma melhor performance após o plantio no campo. Assim, considerando que os tratamentos RM e BJ2 não receberam adubação nitrogenada, uma estratégia interessante é a inoculação em conjunto com a fertilização nitrogenada controlada, visando, ao mesmo tempo, obter maior rapidez na produção de mudas e maior MSN.

\section{CONCLUSÕES}

Nas condições em que o experimento foi realizado, os tratamentos com inoculação foram pouco efetivos em relação ao crescimento das mudas, tendo em vista que as médias das variáveis de crescimento, da MFE e do IQD foram significativamente superiores no $\mathrm{C}^{+}$, em comparação com os demais tratamentos. Entretanto, os isolados RM e BJ2 foram efetivos na produção de nódulos, pois apresentaram os maiores valores médios da MSN. Além disso, os valores médios do ICF foram significativamente superiores nos tratamentos com inoculação em relação ao $\mathrm{C}^{-}$. Os melhores resultados entre os tratamentos com inoculação foram obtidos para RM, seguido de BJ2.

\section{AGRADECIMENTOS}

À CAPES, pela bolsa de Mestrado ao Gabriel S. Góes; e ao CNPq, pelas bolsas de Produtividade em Pesquisa e Desenvolvimento Tecnológico Industrial (DTI-C) a Marcelo S. Mielke e Ediófila Brito-Rocha. Também, aos técnicos do Viveiro Comunitário Floresta Viva Gerson J. Sales Neto, Nilson A. dos Santos e Rones F. Souza e ao Engenheiro-Agrônomo Murilo F. C. de Jesus, pelo auxílio durante a instalação do experimento e a coleta de dados.

\section{REFERÊNCIAS}

ADAMS, M.A.; SIMON, J.; PFAUTSCH, S. Woody legumes: a (re)view from the South. Tree Physiology, v.30, p.1072-1082, 2010.

ADDELMAN, S. The generalized randomized block design. The American Statistician, v.23, n.4, p.35-36, 1969.

CARneiro, J.G.A. Produção e controle de qualidade de mudas florestais. Curitiba: UFPR/FUPEF, 1995. 451p.

CARVALHO, L.R.; SILVA, E.A.A.; DAVIDE,A.C. Classificação de sementes florestais quanto ao comportamento no armazenamento. Revista Brasileira de Sementes, v.28, n.2, p.15-25, 2006.

CHAER, G.M.; RESENDE, A.S.; CAMPELLO, E.F.C.; FARIA, S.M.; BODDEY, R.M.; SCHIMIDT, S. Nitrogen-fixing legume tree species for the reclamation of severely degraded lands in Brazil. Tree Physiology, v.31, n.2, p.139-149, 2011.

COSTE, S.; ROGGY, J.C.; IMBERT, P.; BORN, C.; BONAL, D.; DREYER, E. Leaf photosynthetic traits of 14 tropical rain forest species in relation to leaf nitrogen concentration and shade tolerance. Tree Physiology, v.25, n.9, p.1127$1137,2005$.

DANTAS, P.A.S.; SOUZA JÚNIOR, J.O.S.; GOMES, F.P.; RIBEIRO, D.O. Estimativa nãodestrutiva do teor foliar de nitrogênio em cacaueiro utilizando clorofilômetro. Revista Brasileira de Fruticultura, v.34, n.3, p.669-677, 2012. 
DICKSON, A.; LEAF, A.L.; HOSNER, J.F. Quality appraisal of white spruce and white pine seedling stock in nurseries. The Forestry Chronicle, v.36, n.1, p.10-13, 1960.

DUMROESE, R.K.; JACOBS, D.F.; DAVIS, A.S. Inoculating Acacia koa with Bradyrhizobium and applying fertilizer in the nursery: Effects on nodule formation and seedling growth.

HortScience, v.44, n.2, p.443-446, 2009.

EVANS, J.R. Photosynthesis and nitrogen relationships in leaves of $\mathrm{C} 3$ plants. Oecologia, v.78, n.1, p.9-19, 1989.

FEIJÓ, N.S.A.; MIELKE, M.S.; GOMES, F.P.; FRANCA, S.; LAVINSKY, A.O. Growth and photosynthetic responses of Gallesia integrifolia (Spreng.) Harms and Schinus terebinthifolius Raddi seedlings in dense shade. Agroforestry Systems, v.77, n.1, p.49-58, 2009.

GROSS, E.; CORDEIRO, L.; CAETANO, F.H. Nodule ultrastructure and initial growth of Anadenanthera peregrina (L.) Speg. var. falcata (Benth.) altschul plants infected with rhizobia. Annals of Botany, v.90, p.175-183, 2002.

GROSSNICKLE, S.C. Why seedlings survive: influence of plant attributes. New Forests, v.43, n.5/6, p.711-738, 2012.

HUNT, R. Basic growth analysis. Londres: Unwin Hyman, 1990.

JAYAKUMAR, P.; TAN, T.K. Variations in the responses of Acacia mangium to inoculation with different strains of Bradyrhizobium sp. under nursery conditions. Symbiosis, v.41, n.1, p.3137, 2006.

JOSLIN, A.H.; MARKEWITZ, D.; MORRIS, L.A.; OLIVEIRA, F.A.; FIGUEIREDO, R.O.; KATO, O.R. Five native tree species and manioc under slashand-mulch agroforestry in the eastern Amazon of Brazil: plant growth and soil responses.

Agroforestry Systems, v.81, n.1, p.1-14, 2011.

LOJKA, B.; PREININGER, D.; VAN-DAMME, P.; ROLLO, A.; BANOUT, J. Use of the Amazonian tree species Inga edulis for soil regeneration and weed control. Journal of Tropical Forest Science, v.24, n.1, p.89-101, 2012.
LORENZI, H. Árvores Brasileiras: manual de identificação e cultivo de plantas arbóreas nativas do Brasil. Nova Odessa: Instituto Plantarum, 2008.

MAIA, J.; SCOTTI, M.R. Growth of Inga vera Willd. subsp. affinis under rizobia inoculation. Revista de la Ciencia del Suelo y Nutrición Vegetal, v.10, n.2, p.139-149, 2010.

MAÑAS, P.P.;.CASTRO, E.; LAS HERA, J Quality of maritime pine (Pinus pinaster Ait.) seedlings using waste materials as nursery growing media. New Forests, v.37, n.3, p.295-311, 2009.

MIELKE, M.S.; SCHAFFER, B.; LI, C. Use of a SPAD meter to estimate chlorophyll content in Eugenia uniflora L. leaves as affected by contrasting light environments and soil flooding. Photosynthetica, v.48, n.3, p.332-338, 2010.

MONTGOMERY, R. Relative importance of photosynthetic physiology and biomass allocation for tree seedling growth across a broad light gradient. Tree Physiology, v.24, n.1, p.-167, 2004.

MOREIRA, F.M.S. Nodulação e crescimento de 49 leguminosas arbóreas nativas da Amazônia em viveiro. Revista Brasileira de Ciência do Solo, v.21, n.4, p.581-590, 1997.

PATREZE, C.M.; CORDEIRO, L. Nodulation, arbuscular mycorrhizal colonization and growth of some legumes native from Brazil. Acta Botanica Brasilica, v. 19, n.3, p.527-537, 2005.

SCHROTH, G.; FARIA, D.; ARAUJO, M.; BEDE, L.; VAN BAEL, S.A.; CASSANO, C.R.; OLIVEIRA, L.C.; DELABIE, J.H.C. Conservation in tropical landscape mosaics: the case of the cacao landscape of southern Bahia, Brazil.

Biodiversity and Conservation, v.20, p.1635-1654, 2011.

TORRES-NETTO, A.T.; CAMPOSTRINI, E.; OLIVEIRA, J.G.; SMITH, R.E.B. Photosynthetic pigments, nitrogen, chlorophyll a fluorescence and SPAD-502 readings in coffee leaves.

Scientia Horticulturae, v. 104, n.2, p.199209, 2005.

Revista Árvore, Viçosa-MG, v.39, n.6, p.1031-1038, 2015 
van den BERG, A.K.; PERKINS, T.D. Evaluation of a portable chlorophyll meter to estimate chlorophyll and nitrogen contents in sugar maple
(Acer saccharum Marsh.) leaves. Forest Ecology and Management, v.200, p.113117, 2004. 